\title{
How Viable Is the UTAUT Model in a Non-Western Context?
}

\author{
Kholoud Al-Qeisi ${ }^{1}$, Charles Dennis ${ }^{2}$, Ahmed Hegazy $^{3}$ \& Muneer Abbad ${ }^{4}$ \\ ${ }^{1}$ Applied Science University, Shafa Badran, Amman, Jordan \\ ${ }^{2}$ University of Lincoln, Lincoln Business School, UK \\ ${ }^{3}$ University of Stirling, Stirling, UK; AlAzhar University, Cairo, Egypt \\ ${ }^{4}$ Hashemite University, Zarqa, Jordan \\ Correspondence: Kholoud Al-Qeisi, Applied Science University, Shafa Badran, Amman 11931, Jordan. Tel: \\ 962-777-190-558. E-mail: k.alqeisi@gmail.com
}

Received: January 9, 2015

Accepted: January 22, 2015

Online Published: January 25, 2015

doi:10.5539/ibr.v8n2p204

URL: http://dx.doi.org/10.5539/ibr.v8n2p204

\begin{abstract}
The present research examines the plausibility of the Unified Theory of Acceptance and Use of Technology (UTAUT) model in predicting internet banking behaviour as a newly adopted technology in third world countries. Data is collected from three Arab countries: Jordan, Saudi Arabia and Egypt. Confirmatory factor analysis is used to test the hypothesized structural model. Findings are congruent with model testing under conditions of volitional usage behaviour. In this regard, the role of facilitating conditions variable is insignificant as a determinant of usage behaviour. Social norms variable also proved to be weak determinant of behavioural intentions. Findings demonstrate effort expectancy as the key determinant of internet banking usage behaviour in the examined markets, while users' experience moderates the impact of effort expectancy on behavioural intention. Results should enhance our understanding of internet banking usage in developing countries and support e-services promoting in this region.
\end{abstract}

Keywords: technology acceptance, UTAUT, Arab World, banking industry, online behavior

\section{Introduction}

The accelerating rate of growth in internet adoption in the Arab nations during the past decade has exceeded that of industrial nations (ITU, 2012). Banks in the Arab world are adjusting to technological progress and have introduced e-banking services to maintain their competitive edge. However, in order to take advantage of information technology, banks need to gain better understanding of the differences in consumers' perception and adoption of information technology applications. Differences in information technology usage and adoption are reported to be associated with cultural differences (Straub, 1994; Straub et al., 1997; Straub et al., 2001). The current study is conducted in three countries representative of three areas: Egypt (North Africa) Saudi Arabia (Gulf Region) and Jordan (Mediterranean) with an internet penetration rate of 44, 54 and 41 percent respectively (ITU, 2012).

Literature on technology acceptance comprises models that have been established and developed in the western world and there has been a general concern about the explanatory value of the technology acceptance models when applied to non-western countries (McCoy et al., 2007). Extant research on technology acceptance and usage has led to the formation of the Unified Theory of Acceptance and Use of Technology (UTAUT), a model considered to be a theoretical advance on its precursors and proved popular in the ten years since its inception (Venkatesh et al., 2003).

This paper aims to test the viability of the UTAUT in explaining online banking behaviour in non-western context. An added aim is to investigate whether previously established relationships from the Technology Acceptance Model (TAM) hold in the UTAUT model (Davis, 1989).

\section{Research Background}

The UTAUT is a robust model that provides a unified theoretical basis for technology adoption and diffusion investigations that has been adopted to explain use behaviour in a number of disciplines (Venkatesh et al., 2003). The model comprises four core variables: effort expectancy, performance expectancy, social influences and facilitating conditions. Age, voluntariness of use, experience and gender are expected to moderate the effects of 
these core behavioral beliefs on behavioral intentions and system adoption (Figure 1) (Venkatesh et al., 2003).

\subsection{Performance Expectancy}

Performance Expectancy is the extent to which a user expects that a particular system might assist him/her to gain benefits. These benefits might relate to the overall performance of the job. This factor helps in predicting behavioral intentions in mandatory and optional utilization situations. Moreover, the relationship between performance expectancy and behavioral intention is expected to be moderated by gender and age; the relationship is more significant for men and older people (Venkatesh et al., 2003).

\subsection{Efforts Expectancy}

Efforts Expectancy is the extent to which a certain system offers convenience for usage. Interestingly, the ability of this construct to predict behavioral intentions is only valid during the initial phases of system adoption and that these effects tend to deteriorate over increased duration and consistent utilization (Taiwo \& Downe, 2013). Likewise, the prediction ability is moderated by the factors of age and gender; these impacts would be dominant for females and older people.

\subsection{Social Influences}

Social Influences is the extent to which a person considers the beliefs of other people during the utilization of the system. The predictive ability of this construct is disintegrated under voluntary usage situations and manifest in mandatory usage. Similarly, females and older people are expected more to be influenced by the suggestions and thoughts of other people, mostly during initial phases of adoption; whereas, the impact tends to decline with experience (Venkatesh \& Morris, 2000; Morris \& Venkatesh, 2000).

\subsection{Facilitating Conditions}

Facilitating Conditions is the extent to which an individual feels comfortable to utilize a certain system that is supported by some infrastructures; these infrastructures mostly include technical and organizational infrastructure. Interestingly, this construct predicts behavioral intentions during the initial phases of system adoption and tends to decline with increased system knowledge. In addition, this construct overlaps with effort expectancy; if it is absent in the model, facilitating conditions are expected to be predictive of behavioral intentions (Taiwo \& Downe, 2013). Further, facilitating conditions have a direct influence on usage behavior and such an effect would increase with experience gained. Moreover, older people would be more inclined to ask for support and assistance with new systems.

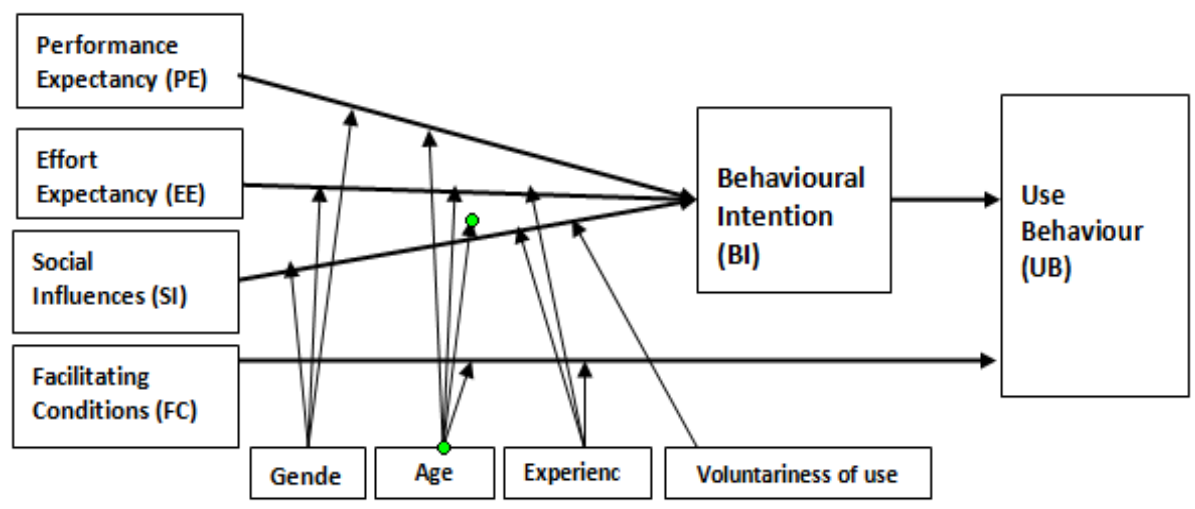

Figure 1. The unified theory of acceptance and use of technology (Venkatesh et al., 2003)

The UTAUT has its roots in Davis' (1989) Technology Acceptance Model (TAM) with its two main constructs. The first one is known as the PU or perceived usefulness, whereas, the second one is known as the PEOU or perceived ease of use. The social impacts and facilitating conditions are also rooted in another famous model, theory of planned behavior (Ajzen, 1985) and its decomposed version (Taylor \& Todd, 1995), which also contributed to TAM extensions: TAM2 (Venkatesh \& Davis, 2000) and TAM3 (Venkatesh \& Bala, 2008). However, the interrelated links among PU-PEOU and social norm (equivalent to social influences) behavior intentions were not tested within the UTAUT; rather, caution was expressed by its authors as not to assume that the links prevail in the aggregated model. This paper attempts to investigate these links. 
Since its inception, the UTAUT has undergone attempts at validation and extension. Oshlyansky validated this model over nine different countries in order to achieve cultural diversification. These samples comprised undergraduate and postgraduate students and the technology under investigation was website access in general. Although the study excluded two constructs from the model, behavioral intention and facilitating condition, three others were added: attitude, anxiety and self-efficacy as antecedents to usage behavior. The finding showed that the UTAUT is sufficiently robust to withstand translation and to be used cross-culturally. Another validation took place across the Middle East region (Lebanon, Iran, Iraq, Kuwait, Bahrain, Qatar, UAE, Oman, Saudi Arabia, Egypt, Sudan, and Djibouti) to investigate employees' disinclination to use a new project management system. In that instance, the finding reported non-support of all hypothesized model links (Jonsson, 2013).

A search of academic and scholarly databases (Ebsco, Emeralds, ProQuest, Science Direct and Google scholar) to locate papers that utilized this model to investigate behavioral intentions and utilization of different applications in the Middle East context resulted in thirteen papers (Table 1), which the present authors examined to uncover the trend and direction of the relationships reported within the model validation. One deduction that can be made is that the findings varied with respect to the strength of prediction for major constructs. The relations hypothesised between constructs in the original UTAUT model with respect to effort expectancy, social influences and facilitating conditions, are inconsistent. On the other hand, apart from one study, performance expectancy maintained its strength as the major predictor of behavioral intentions (Table 2). Performance expectancy has the strongest relationship with behavioral intentions while the impact of social influences on behavioral intentions tends to vary among users of different applications, and the impact of facilitating conditions on usage behaviour is also inconsistent (Dwivedi et al., 2001; Taiwo \& Downe, 2013; Attuquayefio \& Addo, 2014).

Table 1. Studies based on UTAUT in the Arab world

\begin{tabular}{|c|c|c|c|c|c|c|}
\hline Authors/year & Context & Model & Statistics & Sample & location & Results \\
\hline \multicolumn{7}{|c|}{ Mobile technology } \\
\hline $\begin{array}{l}\text { Alkhunaizan, } \\
\text { \& Love } \\
\text { (2012) }\end{array}$ & $\begin{array}{l}\text { Mobile } \\
\text { commerce }\end{array}$ & $\begin{array}{l}\text { Revised: adding cost \& trust } \\
\text { as antecedents to intention } \\
\text { and dropping experience \& } \\
\text { voluntariness } \\
\text { Age \& gender treated as } \\
\text { variables }\end{array}$ & $\begin{array}{l}\text { Factor } \\
\text { Analysis \& } \\
\text { Regression } \\
\text { Analysis }\end{array}$ & $\begin{array}{l}\text { Smart phone } \\
\text { users }\end{array}$ & $\begin{array}{l}\text { Saudi } \\
\text { Arabia }\end{array}$ & $\begin{array}{l}\text { PE significantly predicts usage intentions } \\
\text { followed by cost and EE } \\
\text { Usage BI predict actual usage } \\
\text { FC shows no significant influence on actual } \\
\text { usage. } \\
\text { Gender has no significant difference on usage } \\
\text { while age has. }\end{array}$ \\
\hline $\begin{array}{l}\text { Al Otaibi, } \\
(2013)\end{array}$ & $\begin{array}{l}\text { Mobile } \\
\text { Exchange }\end{array}$ & $\begin{array}{l}\text { Modified: adding mobile } \\
\text { exchange. }\end{array}$ & SEM & $\begin{array}{l}\text { Mobile } \\
\text { traders }\end{array}$ & $\begin{array}{l}\text { Saudi } \\
\text { Arabia }\end{array}$ & $\begin{array}{l}\mathrm{PE}, \mathrm{EE} \text {, and SI predict BI towards use of mobile } \\
\text { exchange (trading stock market), and this is } \\
\text { moderated by age, gender, and education. }\end{array}$ \\
\hline \multicolumn{7}{|l|}{ e-Government } \\
\hline $\begin{array}{l}\text { Al Imarah et al. } \\
\text { (2013) }\end{array}$ & e-services & Original model & CFA-SEM & $\begin{array}{l}\text { Academic } \\
\text { staff }\end{array}$ & Iraq & $\begin{array}{l}\mathrm{PE}, \mathrm{EE} \text {, and FC contribute to the adoption of } \\
\text { e-services and directly impact use behavior. }\end{array}$ \\
\hline $\begin{array}{l}\text { Al-Shafi \& } \\
\text { Weerakkody } \\
\text { (2009) }\end{array}$ & e-services & Original model & $\begin{array}{l}\text { Factor } \\
\text { analysis \& } \\
\text { Logistic } \\
\text { Regression }\end{array}$ & Citizens & Qatar & $\begin{array}{l}\text { PE and SI good predictor of BI } \\
\text { BI good predictor of e-government usage } \\
\text { E-government users differ according to age, } \\
\text { gender, and education. }\end{array}$ \\
\hline $\begin{array}{l}\text { Alshehri et al. } \\
\text { (2013) }\end{array}$ & e-services & $\begin{array}{l}\text { Amended model dropping } \\
\text { use behavioral \& } \\
\text { voluntariness }\end{array}$ & CFA-SEM & Citizens & $\begin{array}{l}\text { Saudi } \\
\text { Arabia }\end{array}$ & $\begin{array}{l}\mathrm{PE}, \mathrm{EE} \text {, and FC positively impact BI; however } \\
\text { moderators (age and gender) have no impact. } \\
\text { Internet experience moderates, EE-IB, SI-BI } \\
\text { and FC-BI }\end{array}$ \\
\hline
\end{tabular}




\begin{tabular}{|c|c|c|c|c|c|c|}
\hline \multicolumn{7}{|l|}{ e-Learning } \\
\hline \multirow{3}{*}{$\begin{array}{l}\text { Jaradat \& } \\
\text { Banikhaled, } \\
\text { (2013) }\end{array}$} & University & \multirow{3}{*}{$\begin{array}{l}\text { Modified by adding } \\
\text { website quality construct } \\
\text { as antecedent to intention }\end{array}$} & \multirow[t]{3}{*}{ Warp PLS 3.0} & \multirow[t]{3}{*}{ Undergrads } & \multirow[t]{3}{*}{ Jordan } & $\mathrm{PE}$ and EE impact BI \\
\hline & Website & & & & & BI directly impact \\
\hline & e-services & & & & & $\begin{array}{l}\text { Experience impact WQ-IB and voluntariness } \\
\text { impact SI-BI }\end{array}$ \\
\hline \multirow{2}{*}{$\begin{array}{l}\text { Nassuora, } \\
(2012)\end{array}$} & Mobile & \multirow{2}{*}{$\begin{array}{l}\text { Modified by adding } \\
\text { Attitude as antecedent to } \\
\text { intention and dropping } \\
\text { use behavior }\end{array}$} & EFA and & \multirow[t]{2}{*}{ Undergrads } & \multirow{2}{*}{$\begin{array}{l}\text { Saudi } \\
\text { Arabia }\end{array}$} & PE and EE impact BI directly \\
\hline & Learning & & $\begin{array}{l}\text { Pearson } \\
\text { Correlation }\end{array}$ & & & SI and FC impact BI indirectly through Attitude. \\
\hline \multicolumn{7}{|c|}{ Social Media Acceptance } \\
\hline \multirow[t]{2}{*}{ Salim, (2012) } & \multirow[t]{2}{*}{ Face book } & \multirow{2}{*}{$\begin{array}{l}\text { Modified by dropping use } \\
\text { behavior }\end{array}$} & Pearson & \multirow{2}{*}{$\begin{array}{l}\text { Egyptian } \\
\text { Face book } \\
\text { users }\end{array}$} & \multirow[t]{2}{*}{ Egypt } & EE and SI significantly impact BI \\
\hline & & & Correlation & & & $\begin{array}{l}\text { FC has a significant impact on BI moderated by } \\
\text { age and experience }\end{array}$ \\
\hline \multicolumn{7}{|c|}{ Information Technology (IT) } \\
\hline \multirow{2}{*}{$\begin{array}{l}\text { Al-Gahtani et } \\
\text { al. (2007) }\end{array}$} & Desktop & \multirow{2}{*}{$\begin{array}{l}\text { Modified: dropping } \\
\text { voluntariness, } \\
\text { substituting SI with SN }\end{array}$} & \multirow[t]{2}{*}{ PLS - Graph } & \multirow{2}{*}{$\begin{array}{l}\text { Knowledge } \\
\text { workers in } 4 \\
\text { organizations }\end{array}$} & \multirow{2}{*}{$\begin{array}{l}\text { Saudi } \\
\text { Arabia }\end{array}$} & PE - BI and moderated by age only \\
\hline & Computer & & & & & SN-BI and moderated by experience and age only. \\
\hline \multicolumn{7}{|l|}{ e-Banking } \\
\hline \multirow{4}{*}{$\begin{array}{l}\text { Abu Shanab \& } \\
\text { Pearson } \\
\text { (2007) }\end{array}$} & \multirow{4}{*}{$\begin{array}{l}\text { Internet } \\
\text { Banking }\end{array}$} & \multirow{4}{*}{$\begin{array}{l}\text { Modified by dropping } \\
\text { facilitating conditions and } \\
\text { use behavior from the } \\
\text { model. }\end{array}$} & \multirow{4}{*}{$\begin{array}{l}\text { Factor } \\
\text { analysis \& } \\
\text { Multiple } \\
\text { Regression }\end{array}$} & \multirow{4}{*}{$\begin{array}{l}\text { Internet } \\
\text { banking } \\
\text { users }\end{array}$} & \multirow[t]{4}{*}{ Jordan } & PE-IB moderated by gender and age \\
\hline & & & & & & EE-BI moderated by sex and age \\
\hline & & & & & & $\begin{array}{l}\text { SI-IB significant moderated by gender and } \\
\text { experience }\end{array}$ \\
\hline & & & & & & EE-IB and FC-IB not significant \\
\hline \multirow{2}{*}{$\begin{array}{l}\text { AlMashaqba \& } \\
\text { Nassar } \\
\text { ( 2012) }\end{array}$} & \multirow{2}{*}{$\begin{array}{l}\text { Mobile } \\
\text { Banking }\end{array}$} & \multirow[b]{2}{*}{$\begin{array}{l}\text { Modified by adding } \\
\text { security, design issues, } \\
\text { reliability as antecedent to } \\
\text { intention and education as } \\
\text { moderator while dropping } \\
\text { other moderators }\end{array}$} & \multirow{2}{*}{$\begin{array}{l}\text { Factor } \\
\text { analysis and } \\
\text { KMO }\end{array}$} & \multirow[t]{2}{*}{ Bank clients } & Jordan & PE, SI only impact BI \\
\hline & & & & & & $\begin{array}{l}\text { PE-BI and FC-Use is moderated by experience } \\
\text { and education }\end{array}$ \\
\hline AlQeisi \& & Internet & Extended by replacing FC & FCA-SEM & Internet & Jordan & PE-usage directly and EE-usage indirectly \\
\hline Al-Abdellah & Banking & with web quality design & & banking & & through PE \\
\hline$(2013)$ & & and dropping BI. & & users & & $\begin{array}{l}\text { Web quality-usage behavior impact is higher } \\
\text { than PE-usage }\end{array}$ \\
\hline & & & & & & SN- usage is non-significant \\
\hline
\end{tabular}

Table 2. Relationships amongst constructs in research carried out in Arab countries

\begin{tabular}{lccccc}
\hline & PE-BI & EE-BI & SI-BI & FC-BU & BI-BU \\
\hline Abu Shanab \& Pearson (2007) & sig & sig & sig & NA & NA \\
Al-Gahtani et al. (2007) & sig & non-sig & sig & non-sig & NA \\
Al Imarah et al. (2013) & sig & sig & non-sig & sig & sig \\
Al khunaizan \& Love (2012) & sig & sig & sig & non-sig. & sig \\
Al Mashaqba \& Nassar (2012) & sig & non-sig & sig & Sig & sig \\
Al Otaibi, B. (2013) & sig & sig & sig & NA & NA \\
Al-Qeisi \& Al-Abdellah (2013) & NA & NA & NA & Sig & NA \\
Al-Shafi \& Weerakkody (2009) & sig & non-sig & sig & non-sig & sig \\
Alshehri et al. (2013) & sig & sig & non-sig & NA & NA \\
Alwahaishi \& Snášel (2013) & sig & non-sig & sig & Sig & sig \\
Jaradat \& Banikhaled, (2013) & sig & sig & non-sig & non-sig & sig \\
Nassuora, (2012) & sig & sig & non-sig & non-sig & NA \\
Salim, B. (2012) & non- sig. & sig & sig & NA & NA \\
\hline
\end{tabular}

N/A: not applicable (not hypothesized). 
This work replicates the original UTAUT study and explores determinants of internet banking usage behavior in three Middle Eastern countries, in addition to investigating the previously established relations among the equivalent constructs in the root models. However, voluntariness of use is not tested as a moderator in the model simply because; online banking is a voluntary choice by nature of service.

\section{Method}

\subsection{The Sampling and Data Collection}

Samples were extracted from the three markets using an online and offline questionnaire. The operational definition of the variable and scaling is based on the original study by the authors of the UTAUT model and adapted to internet banking usage behavior (Appendix 1). The research instrument was first converted into Arabic and then it was again converted into English. Preliminary tests were conducted for the instrument in different countries. In this regard, two commonly accepted techniques were used that includes pilot sampling and focus group. These techniques assisted in validating the meanings, comprehension and functionality according to the rules and desired time. Minor changes to wordings were applied in the three versions of the online survey. There were 776 usable surveys extracted from all markets. The samples demographics are presented in Table 3. Respondents are knowledgeable about computers and internet $(63 \%$ and $75 \%$ ranged between good and very good) with $48 \%$ reporting more than 5 years of internet adoption and $27 \%$ more than two years for Internet banking usage. The demographics show that the samples are fairly young, with $70 \%$ aged between $26-46$, and well- educated (55\% undergraduates, $20 \%$ graduates and $10 \%$ postgraduate). Females comprised only $35 \%$ of the sample, while males predominated, with $65 \%$. The majority (67\%) reported personal motivation for internet banking usage, while work motivation amounted to $12 \%$ and dual motivation $21 \%$. Most respondents report the high level of satisfaction with their online banking service providers (59\% indicated a level of satisfaction above 4).

Table 3. Demographic profile of respondents

\begin{tabular}{|c|c|c|c|}
\hline Respondent Profile & Category & Frequency & Percentage \\
\hline & Poor & 30 & 3.9 \\
\hline & Moderate & 254 & 32.7 \\
\hline \multirow[t]{4}{*}{ Computer Knowledge } & Good & 224 & 28.9 \\
\hline & Very good & 268 & 34.5 \\
\hline & Poor & 20 & 2.6 \\
\hline & Moderate & 174 & 22.4 \\
\hline \multirow[t]{4}{*}{ Internet knowledge } & Good & 299 & 38.5 \\
\hline & Very good & 283 & 36.5 \\
\hline & Less than one year & 150 & 19.3 \\
\hline & $1-2 \mathrm{yrs}$ & 149 & 19.2 \\
\hline \multirow[t]{4}{*}{ Internet experience } & $3-4$ yrs & 108 & 13.9 \\
\hline & More than 5 yrs & 369 & 47.6 \\
\hline & Less than six months & 133 & 17.1 \\
\hline & $6-12$ months & 132 & 29.9 \\
\hline \multirow[t]{4}{*}{ Internet Banking usage } & $13-18$ months & 131 & 16.9 \\
\hline & $19-24$ months & 67 & 8.6 \\
\hline & More than 24 months & 213 & 27.4 \\
\hline & Personal & 519 & 66.9 \\
\hline \multirow[t]{2}{*}{ Usage motivation } & Business & 92 & 11.9 \\
\hline & Both & 165 & 21.3 \\
\hline
\end{tabular}




\begin{tabular}{|c|c|c|c|}
\hline \multirow{7}{*}{$\begin{array}{l}\text { Level of satisfaction with current } \\
\text { i-services }\end{array}$} & 1 & 3 & 0.4 \\
\hline & 2 & 17 & 2.2 \\
\hline & 3 & 102 & 13.1 \\
\hline & 4 & 195 & 25.1 \\
\hline & 5 & 222 & 28.6 \\
\hline & 6 & 153 & 19.7 \\
\hline & 7 & 84 & 10.8 \\
\hline \multirow{5}{*}{ Age } & $25 \mathrm{yrs}$ and less & 166 & 21.4 \\
\hline & $26-35 \mathrm{yrs}$ & 361 & 46.5 \\
\hline & $36-46 \mathrm{yrs}$ & 183 & 23.6 \\
\hline & $47-57 \mathrm{yrs}$ & 51 & 6.6 \\
\hline & $58 \mathrm{yrs}$ and more & 15 & 1.9 \\
\hline \multirow{5}{*}{ Education } & High school and below & 85 & 11.0 \\
\hline & Bachelor & 424 & 54.6 \\
\hline & Masters & 157 & 20.2 \\
\hline & Doctorate & 81 & 10.4 \\
\hline & other & 29 & 3.6 \\
\hline \multirow[b]{2}{*}{ Gender } & Male & 506 & 65.2 \\
\hline & Female & 270 & 34.8 \\
\hline
\end{tabular}

Data was initially screened and treated for missing data, using estimation, before being combined and treated for multivariate normality based on Byrne's guidelines (Byrne, 2010, pp. 104-106). The data was tested as a single set to evaluate how the model performs on a diverse and mixed sample. The sample size after treatment was 677. Confirmatory factor analysis indicated that facilitating conditions construct and two social influence items are candidates for elimination. The fit measures satisfy the standard criteria: $\chi^{2}=142.9, \mathrm{df}=55, \chi^{2} / \mathrm{df}=2.60$, CFI $=.990, \mathrm{GFI}=0.971, \mathrm{RMSEA}=0.047$.

Convergent validity measured by reliability, variance and factor loadings is presented in Table 4 . The Average variance extracted (AVE) values are greater than the squared correlations among variable indicating an acceptable discriminant validity Average variance extracted (AVE) values are greater than the squared correlations between constructs (Table 5), indicating acceptable discriminant validity (Hair et al., 2006).

Table 4. Standardized factor loadings, variances extracted, and reliability estimates

\begin{tabular}{|c|c|c|c|c|c|}
\hline & PE & $\mathbf{E E}$ & SI & BI & USE \\
\hline PE1 & .842 & & & & \\
\hline PE2 & .939 & & & & \\
\hline PE3 & .882 & & & & \\
\hline EE2 & & .820 & & & \\
\hline EE3 & & .885 & & & \\
\hline EE4 & & .844 & & & \\
\hline SI1 & & & .893 & & \\
\hline SI2 & & & .875 & & \\
\hline BI1 & & & & .904 & \\
\hline BI2 & & & & .950 & \\
\hline BI3 & & & & .939 & \\
\hline USE1 & & & & & .795 \\
\hline USE2 & & & & & .882 \\
\hline AVE & .790 & .723 & .782 & .867 & .705 \\
\hline Reliability & .916 & .884 & $r^{2}=.887$ & .951 & $r^{2}=.824$ \\
\hline
\end{tabular}


Table 5. Squared correlation matrix

\begin{tabular}{llllll}
\hline & USE & BI & SI & PE & EE \\
\hline USE & $\mathbf{. 7 0 5}$ & & & & \\
BI & .684 & $\mathbf{. 8 6 7}$ & & & \\
SI & .354 & .243 & .782 & .288 & .790 \\
PE & .637 & .630 & .323 & .697 & $\mathbf{. 7 2 3}$ \\
EE & .678 & .664 &
\end{tabular}

Note. Average variances extracted are on the diagonal. The values below the diagonal are the relations between various constructs that are squared.

\subsection{Structural Model}

The structural model comprised only three behavior determinants: performance expectancy, social influences and effort expectancy. The hypothesized paths in the original UTAUT model (Table 6) and regression weights indicate that all three constructs impact behavioral intentions significantly; however social influences has the lowest impact. In addition, the model fit readings were not acceptable, which calls for the elimination of social influences in order to improve model fit indices.

Table 6. Path estimate for the original model

\begin{tabular}{cccc}
\hline Path & Estimate & Standard Error & t \\
\hline BI <--- PE & .501 & .043 & $11.601 * * *$ \\
BI <--- EE & .537 & .045 & $11.848^{* * *}$ \\
BI <--- SI & .063 & .028 & $2.255^{*}$ \\
USE<--- BI & .838 & .036 & $22.983^{* * *}$ \\
\hline
\end{tabular}

Note. $*=\mathrm{p}<0.05 ; * * *=\mathrm{p}<0.001$.

The final structural model comprised only the two behavioral determinants: performance expectancy and effort expectancy; with the latter having higher impact on behavioral intentions (a standardized regression weight is .568 vs. .536 and standardized total effect is .479 vs. .453).

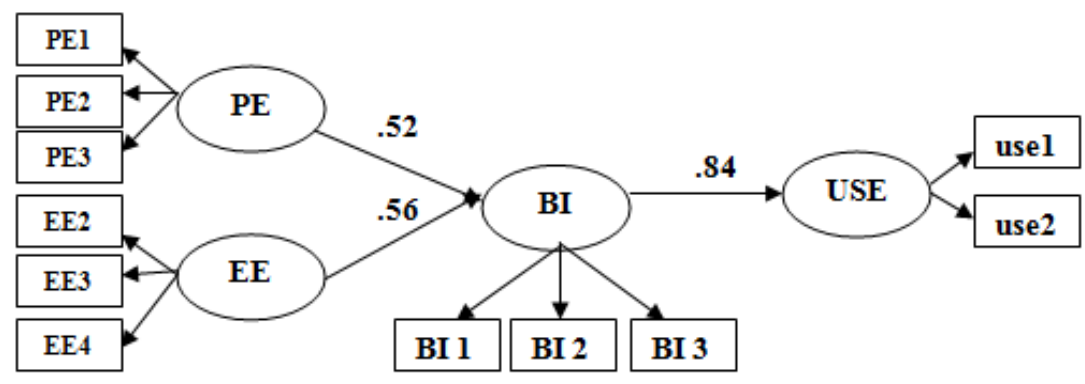

Figure 2. The final structural model

The structural model with two behavioral beliefs explained 84 percent of use behavior, a percentage that is higher than acquired by the original UTAUT model (70\%).

\subsection{The Mediating Effect of PE}

The original UTAUT study does not test previously established relationships among the TAM constructs and the mediating role of performance expectancy (equal to PU) between effort expectancy (equal to PEOU) and behavioral intentions (Venkatesh et al., 2003). Nevertheless, other research does report these links (Al-Qeisi \& 
Al-Abdellah, 2003; Al-Qeisi et al., 2014). These links are confirmed statistically in this current study. As Figure 3 illustrates, the standardized regression coefficient between Performance Expectancy and Effort Expectancy is statistically significant, as is the standardized regression coefficient between Performance Expectancy and Behavioral Intentions. The standardized indirect effect was (.313). Using bias-corrected bootstrap at 95\% confidence intervals, significance of this indirect effect is tested (Cheung \& Lau, 2008); the bootstrapped unstandardized indirect effect is .357 , and the $95 \%$ confidence interval ranges from $.240, .481$, hence, the indirect effect is statistically significant $(\mathrm{p}=0.001)$ implying partial mediation.

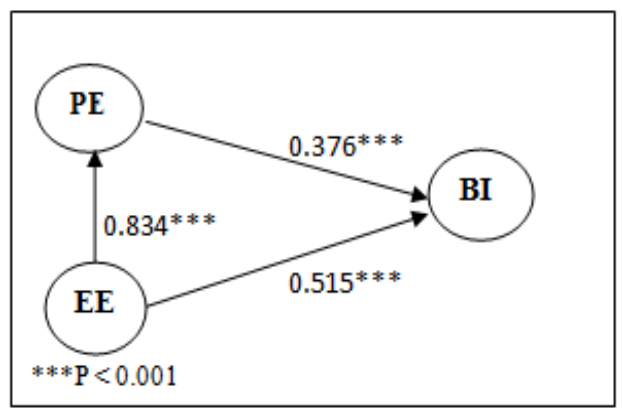

Figure 3. The mediation role of PE

Adding the path EE-PF resulted in improved path estimates. However, the impact of effort expectancy on behavioral intentions is still higher than performance expectancy's impact (Table 7). The model fit also improved; the fit measures satisfy the standard criteria: $\chi^{2}=179.4, \mathrm{df}=40, \chi^{2} / \mathrm{df}=4.49, \mathrm{CFI}=0.982$, GFI $=0.957$, RMSEA $=0.060$.

Table 7. Path estimations for hypothesized model

\begin{tabular}{cccc}
\hline Path & Estimate & Standard Error & $\mathbf{t}$ \\
\hline BI $<---$ PE & .428 & .059 & $7.3^{* * *}$ \\
BI <--- EE & .587 & .061 & $9.7^{* * *}$ \\
PE<--- EE & .835 & .038 & $22.2^{* * *}$ \\
USE<--- BI & .837 & .036 & $23.0^{* * *}$ \\
\hline
\end{tabular}

Note. $* * *=\mathrm{p}<.001$.

\subsection{Impact of Moderators}

Before testing for moderation, measurement invariance is established: the degree to which various items possess significance across different categories that are similar (French \& Finch, 2006). All group models were tested separately and based on satisfactory data fit indices, multi-group analysis was run in IBM SPSS Amos and all groups were invariant $\Delta \mathrm{CFI}<.01$ (Byrne et al., 2007) (Table 8).

\subsection{Effort Expectancy - Performance Expectancy (EE-PE)}

The regression weight estimates demonstrate that perceptions of lower-effort internet banking system impact system's performance expectancy in a way that is higher for males than females (.828 vs. .807); for the older age group than the younger age group (.876 vs. .762); and for highly computer and internet experienced individuals than moderately experienced individuals (.815 vs. .727) However, for all these groups EE-PE path coefficients differences are non-significant ( $\mathrm{t}$ value $<2$ ). The amount of variance accounted for in performance expectancy by effort expectancy (Table 9) is higher for women than for men (.751 vs. .656); for older age group than younger group (.772 vs. .619) and for moderately experienced individuals than for highly experienced (.719 vs. .641).

\subsection{Performance Expectancy - Behavioral Intentions (PE-BI)}

Based on the regression weight estimates of multi-group analysis, the impact of performance expectancy on 
behavioral intentions is higher for males than females (.459 vs. .348), for younger age group than older age group (.518 vs. .434) and for high experience group than moderate experience group (.470 vs. .161). However, all groups PE-BI path coefficients differences are non-significant ( $\mathrm{t}$ value $< \pm 2$ ).

\subsection{Effort Expectancy - Behavioral Intentions (EE-BI)}

Effort expectancy is a greater direct determinant of behavioral intentions for females compared to males based on the regression weights output (.674 vs. .542). The impact is slightly different between the two age groups (.579 vs. .523); however, the impact is more profound for moderately experienced individuals compared to highly experienced individuals (.828 vs. .502). The path coefficient is also higher for moderate experience group compared to high experience group (.773 vs. .442$)$ and in this case the difference is significantly different (t value $=2.076$ )

\subsection{Behavioral Intentions - Use Behavior (BI-USE)}

Behavioral intentions determine use behavior similarly for both genders (.808 and .860 ) but slightly higher for old people against the youngsters (.977 vs. .879) and for highly experienced individuals compared to moderately experienced (.857 vs. .769). However, these path coefficients differences are non-significant (t value <2). The amount of variance accounted for in use behavior by behavioral intentions is a little higher for males than females, for moderately experienced group compared to highly experience group (Table 9).

Table 8. AMOS output for moderates statistics

\begin{tabular}{|c|c|c|c|c|c|c|c|c|c|c|c|c|c|c|}
\hline \multirow{2}{*}{ Gender } & $\begin{array}{c}\begin{array}{c}\text { Overall } \\
\text { multi-group } \\
\text { model fit indices }\end{array} \\
\end{array}$ & \multirow{2}{*}{$\begin{array}{l}\text { Multi-group } \\
\text { analysis } \\
\text { statistics }\end{array}$} & \multirow[t]{2}{*}{ CFI } & \multirow[t]{2}{*}{$\Delta \mathrm{CFI}$} & \multirow[t]{2}{*}{ Paths } & \multicolumn{4}{|c|}{ Group 1} & \multicolumn{5}{|c|}{ Group 2} \\
\hline & \multirow{6}{*}{$\begin{array}{c}\chi^{2}=228.7, \mathrm{df}=80 \\
\chi^{2} / \mathrm{df}=2.86 \\
\mathrm{GFI}=0.947 \\
\mathrm{CFI}=0.981 \\
\text { RMSEA }=0.051\end{array}$} & & & & & $\begin{array}{c}\text { M. } \\
\text { R.W }\end{array}$ & S.E & $\mathbf{t}$ & S.R.W & $\begin{array}{c}\text { F. } \\
\text { R.W }\end{array}$ & S.E & $\mathrm{t}$ & S.R.W & t-diff. \\
\hline & & Unconstrained & .981 & & EE -PE & .828 & .048 & 17.17 & .810 & .807 & .059 & 13.71 & .867 & 0.276 \\
\hline & & Measurement weights & .981 & .000 & PE - BI & .459 & .069 & 6.61 & .406 & .348 & .116 & 3.01 & .294 & 0.822 \\
\hline & & Structural Weights & .981 & .000 & EE - BI & .542 & .073 & 7.44 & .469 & .674 & .112 & 6.03 & .613 & -0.987 \\
\hline & & & & & BI - USE & .808 & .045 & 17.85 & .890 & .860 & .062 & 13.87 & .870 & -0.678 \\
\hline & & & & & & & & & & & & & & \\
\hline \multirow[t]{6}{*}{ Age } & & & & & & $\begin{array}{l}\text { Age1 } \\
\text { R.W }\end{array}$ & S.E & $\mathbf{t}$ & S.R.W & $\begin{array}{l}\text { Age2 } \\
\text { R.W }\end{array}$ & S.E & $\mathbf{t}$ & S.R.W & t-diff. \\
\hline & $\chi^{2}=172.4, \mathrm{df}=78$ & Unconstrained & .981 & & $\mathrm{EE}-\mathrm{PE}$ & .762 & .097 & 7.83 & .787 & .876 & .053 & 16.56 & .879 & -0.226 \\
\hline & $\chi^{2} / \mathrm{df}=2.210$ & Measurement weights & .983 & .002 & PE - BI & .518 & .129 & 4.01 & .446 & .434 & .096 & 4.53 & .377 & 0.447 \\
\hline & GFI $=0.937$ & Structural Weights & .983 & .002 & EE - BI & .523 & .126 & 4.15 & .465 & .579 & .098 & 5.93 & .505 & 0.363 \\
\hline & $\mathrm{CFI}=0.981$ & & & & BI - USE & .879 & .121 & 7.25 & .994 & .977 & .060 & 16.37 & .989 & -0.851 \\
\hline & RMSEA $=0.050$ & & & & & & & & & & & & & \\
\hline \multirow[t]{7}{*}{ Exp. } & & & & & & $\mathbf{M}$ & S.E & $\mathbf{t}$ & S.R.W & $\mathbf{H}$ & S.E & $\mathbf{t}$ & S.R.W & t-diff. \\
\hline & & & & & & R.W & & & & R.W & & & & \\
\hline & $\chi^{2}=246.1, \mathrm{df}=80$ & Unconstrained & .977 & & $\mathrm{EE}-\mathrm{PE}$ & .727 & .074 & 9.82 & .848 & .815 & .046 & 17.68 & .801 & -1.009 \\
\hline & $\chi^{2} / \mathrm{df}=3.07$ & Measurement weights & .976 & .001 & PE -BI & .161 & .151 & 1.06 & .129 & .470 & .064 & 7.31 & .422 & -1.884 \\
\hline & $\mathrm{GFI}=0.942$ & Structural Weights & .976 & .001 & EE -BI & .828 & .142 & 5.81 & .773 & .502 & .067 & 7.48 & .442 & 2.076 \\
\hline & $\mathrm{CFI}=0.977$ & & & & BI -USE & .769 & .085 & 9.06 & .886 & .857 & .044 & 19.48 & .854 & -0.919 \\
\hline & RMSEA $=0.054$ & & & & & & & & & & & & & \\
\hline
\end{tabular}

Note. R.W. = regression weights; S.E. $=$ standard error of the regression weights; S.R.W. $=$ standardized regression weights; $\mathrm{t}=\mathrm{t}$-value of the regression coefficient (critical ratio); $\mathrm{t}$-diff. = t-value of the difference between Groups 1 and 2; Gender $\mathrm{M}=\mathrm{Males}$; $\mathrm{F}=$ Females; age $1=26$ $<35$; age $2=35$ - <46 years; Exp. = experience; $\mathrm{M}$ = moderate; $\mathrm{H}=$ high . 
Table 9. Groups estimates of variance explained (squared multiple correlations)

\begin{tabular}{ccccccc}
\hline Variable & Males & Females & Age1 & Ag2 & Moderate experience & High experience \\
\hline PE & .656 & .751 & .619 & .772 & .719 & .641 \\
BI & .692 & .775 & .742 & .733 & .783 & .671 \\
USE & .792 & .757 & .678 & .726 & .785 & .729 \\
\hline
\end{tabular}

\subsection{Differences between Country Samples}

Using the final structural model (Figure 2) as the baseline model, multiple-group analysis is run between the three country samples. Table 10 reports the model fit indices for the three samples. Egyptian and Jordanian samples have an acceptable model fit whereas the Saudi sample is out of range on most of the fit statistics.

Table 10. Model fit indices for country samples

\begin{tabular}{ccccccc}
\hline & $\chi^{2}$ & df & $\chi^{2} /$ df & \multicolumn{1}{c}{ GFI } & \multicolumn{1}{c}{ CFI } & RMSEA \\
\hline Egypt & 102.943 & 40 & 2.574 & 0.945 & 0.979 & 0.069 \\
Jordan & 79.591 & 40 & 1.990 & 0.942 & 0.985 & 0.067 \\
Saudi Arabia & 121.326 & 40 & 3.033 & 0.890 & 0.954 & 0.108 \\
\hline
\end{tabular}

The Jordan and Egypt samples are check for invariance using multi-group analysis. The samples model fit indices are acceptable: $\chi 2=182.5 \mathrm{df}=80$ and $\chi 2 / \mathrm{df}=2.28$; GFI= 0.944; CFI= 0.982; RMSEA $=0.048$. Running the invariance analysis showed that path PE-IB is non-significant for the Egyptian sample. All other paths are significant as reported in Table 11. In addition, the $\Delta$ CFI values support the invariance assessment of the multi-groups (all values <.01).

Table 11. Non standardized path estimates for country groups

\begin{tabular}{|c|c|c|c|c|c|c|c|c|c|}
\hline \multirow[t]{2}{*}{ Path } & \multicolumn{4}{|c|}{ Egypt } & \multicolumn{4}{|c|}{ Jordan } & \multirow{2}{*}{$\begin{array}{c}\text { t-diff. } \\
\text { Egypt-Jordan }\end{array}$} \\
\hline & R.W & S.E & $\mathbf{t}$ & S.R.W & R.W & S.E & $\mathbf{t}$ & S.R.W & \\
\hline EE - PE & .792 & 0.057 & 14.003 & .897 & .793 & 0.067 & 11.755 & .778 & -0.01137 \\
\hline PE - BI & .214 & .153 & 1.397 & .168 & .349 & 0.094 & 3.725 & .305 & -0.7518 \\
\hline EE - BI & .844 & .143 & 5.908 & .750 & .622 & 0.099 & 6.248 & .534 & 1.27641 \\
\hline BI- USE & .911 & 0.057 & 16.071 & .950 & .838 & 0.058 & 14.377 & .867 & 0.897684 \\
\hline
\end{tabular}

Note. R.W. (regression weights) S.R.W. (standardized regression weights).

The standardized regression weights showed that effort expectancy has the highest impact on behavioral intentions for both samples, and that impact is almost identical. However, the hypothesized path PE-BI was not significant for Egypt. It seems that the internet banking users in Egypt are motivated by effort expectancy, ease of use, more than system performance and efficiency. All path coefficients are non-significant (t-values <2) between the two country groups.

The Saudi sample modification indices suggested a direct path from effort expectancy to usage behavior. Adding such path is acceptable and has a basis in the literature (Venkatesh, 1999; Davis et al., 1989; Venkatesh \& Morris, 2000; Agarwal \& Prasad, 1999). Adding this path also improves the model fit readings: $\chi 2=90.462, \mathrm{df}=40$ and $\chi 2 / \mathrm{df}=2.312, \mathrm{GFI}=0.912, \mathrm{CFI}=0.970$, and RMSEA $=0.081$. The standardized regression weight for the path EE-USE weights is close to that of BI-USE (.472 and .473 respectively). However, the standardized total effect shown in Table 12 demonstrates that the effort expectancy has the highest impact on use behavior, both direct and indirect through performance expectancy, followed by behavioral intentions. 
Table 12. Standardized total effect

\begin{tabular}{lllll}
\hline & EE & PE & BI & USE \\
\hline PE & .766 & .000 & .000 & .000 \\
BI & .593 & .775 & .000 & .000 \\
USE & .767 & .377 & .486 & .000 \\
\hline
\end{tabular}

\section{Discussion}

This work examines the viability of the aggregated technology acceptance model in non-western cultures within an online context. The results reveal that the UTAUT is applicable in explaining online behavior in non-western cultures under discretionary use limitations. In particular, importance of the facilitating conditions did not materialize given that participants are actual users of the internet banking system and the existence of effort expectancy in the model, which according to the UTAUT authors, overlaps with facilitating conditions and lead to weakening effect of the latter (Venkatesh et al., 2003). The effects of social influences on behavioral intentions were also weak which is consistent with technology acceptance research attributing such findings to the moderating effect of experience and voluntariness (Karahanna et al., 1999). Moreover, such unimportant effects of social influences on behavioral intentions within the UTAUT context are also reported findings under different web-based technology applications: for example e-government services and e-learning (Alshehri et al., 2013; Al Imarah et al., 2013; Jaradat \& Banikhaled, 2013; Nassuora, 2012).

Once these two constructs are eliminated from the model, the behavioral beliefs effort expectancy and performance expectancy accounted for much of the differences in the behavioral intention construct. The findings point to effort expectancy as the key determinant of behavioral intentions in the three samples, which disconfirms the original UTAUT model where performance expectancy is purported to represent the key determinant of use behavior through behavioral intention. However, literature reports that the only context in which the influence of effort expectancy on behavioral intentions is crucial in internet applications (King and He, 2006). This finding implies that Arab internet banking users' decisions on technology adoption are influenced significantly by the ease of use that technology offers, in line with other previous research in the Arab world. For example, Jaradat \& Banikhalid found effort expectancy to have the strongest effect on behavioral intentions among students in Jordan using a university website (Jaradat \& Banikhalid, 2009). Nassuora finds effort expectancy to be more predictive of behavior intention among Saudi students within mobile learning context (Nassuora, 2012). One explanation for such a powerful impact of effort expectancy as compared to performance expectancy might lie in the fact that internet banking services are still in their introductory stage in these countries and the numbers of services/tasks that can be executed are still rather basic (i.e. $80 \%$ of current respondents use the online access for basic services such as enquiring about balances, accessing accounts, transferring money between accounts and paying utility bills). Abbad et al. (2012) reports similar findings.

The impact of performance expectancy on behavioral intention is unimportant in the Egyptian model. This finding implies that Egyptians are more motivated by system low-effort expectancy than performance expectancy, in accordance with previous studies (El- Kasheir et al., 2009; Salim, 2012). El- Kasheir reports bank clients may be drawn to the online services at first by its performance efficiency but with habit, repeated use and gained experience, the ease of use may become the salient factor (El- Kasheir, et al., 2009). Furthermore, TAM research across cultures indicates that the PEOU is the salient determining factor of usage in Arab developing countries (Elbeltagi et al., 2005; Rouibah, 2008; Khushman et al., 2010).

A contribution of this work is testing the partial mediating role of performance expectancy between effort expectancy and behavioral intentions. In the original model, the two behavioral beliefs are not related, and each uniquely explains a level of variance in use behavior through behavioral intentions. Contrariwise, this current study demonstrates that the mediation role of performance expectancy connects the two beliefs amplifying user perceptions of system effort expectancy (ease of use) as a window to assess system efficiency (task completion at minimal effort) and building perceptions of channel usefulness.

The impact of moderators on the model structure was invariant among gender groups, age and experience. However, paths regression weights showed small differences among groups. Males' perceptions of effort expectancy influence perceptions of performance expectancy slightly higher than females; also males' perceptions of system performance expectancy impact their behavioral intentions more than females whereas females' behavioral intentions are more induced by system effort expectancy. However, both genders are closely 
similar with respect to behavioral intentions impact on use behavior.

Age differences among respondents suggest that mature users' behavioral intentions may be motivated by system effort expectancy more than the younger group and their intentions may have a slightly higher impact on actual use behavior whereas the younger group behavioral intentions may be more driven by system performance expectancy. However, these differences are non-significant.

Experience has the only significant moderating effect on the path effort expectancy-behavioral intentions that medium experienced internet banking users are more motivated by system low-effort than high experienced users On the other hand, high experienced users may be more motivated by system usefulness or performance expectancy although that difference is non- significant.

\subsection{Implications for Practice}

The findings suggest that online banking is still in its infancy stage in the Arab countries studied, the inference that respondents are using the online channel access to perform basic tasks means that the service has not matured sufficiently to replace the traditional channels fully. Practitioners' may encourage people to use more electronic services by increasing the value perceptions though means such as taking no fees or charges or offering more benefits such as convenience and confidentiality. The findings also reveal that effort expectancy is the main determinant of behavioral intentions and behavioral use. This implies that people are drawn to an online service motivated by the ease of use, implying the existence of a user-friendly website interface. Although moderators had no real impact on the model, the level of computer and internet experience differences imply that with spread use of e-services, experienced users are drawn by the e-banking efficiency characteristics. Additionally, the majority of users are young people aged 25-35, the active online generation in Arab countries (IUT reports, 2013), which indicates the need for more focused attention to the requirement of this generation (e.g. extending more credit facilities in view of increased interest in e-commerce amongst young shoppers).

\section{Limitations of the Study}

As with any study, limitations need to be considered in the interpretation of the results. First, the study is a cross-sectional research and results need to be confirmed using a longitudinal study. Further longitudinal studies may offer insights into how usage determinants change overtime. Second, the samples were not parallel in size after treatment to meet multivariate normality, the result produced imbalanced sizes. Saudi sample size (196) was smaller compared to Jordan's (221) and the (260) of Egypt; hence, the findings of the Saudi sample should be confirmed through a larger sample. Third, the results are restricted to internet banking users in the three Arab countries, consequently, due to cultural and technological factors; the results may not be confirmed when examining other e-banking channels in other Arab countries. As a general rule, in order to verify the research results, the research should be expanded geographically and to other banking choices as well, e.g. mobile banking. Fourth, the present study investigated the internet banking behavior as a means to examine the viability of the UTAUT model in non-western context. This means that the behavior examined was entirely centered on the salient beliefs as the UTAUT model suggests. The model, however, does not take into consideration other factors that may inhibit the online banking behavior such as online security, pricing, elements of web design. Finally, the variables of the model were measures using self-report design, which means that the results may be influenced by common method bias or social desirability tendency that might have distorted the mean for samples information.

\section{Conclusion}

This study compared users' adoption behavior of internet banking in the non-western context in particular Arab countries by applying the UTAUT model (Venkatesh et al., 2003). The model fits under condition of voluntary use behavior and experienced users, provides evidence of technology globalization; while differences between western and non-western countries in terms of the impact effort expectancy indicates the continuance existence of some cultural differences. Furthermore, performance expectancy is a not a significant influence on behavioral intentions in Egypt consistent with previous studies; hence effort expectancy possesses a noteworthy significance as it affects both behavioral intentions/usage and performance expectancy which justifies attention to cultural differences. In context of further studies, it is necessary to examine the model viability using a larger sample to confirm the research findings. It would also be interesting to investigate further the model viability in other geographical areas within the Arab world (e.g. Arab Maghreb or West North Africa). Moreover, in order to increase the explanatory power of the UTAUT model additional factors should be considered (i.e. bank website aspects of privacy and interactivity). There is also a need to develop further direct measures to increase accuracy and validity of the conceptual model and minimize bias and social desirability tendency among respondents. Finally, with the evolution of new applications, this research can be applied using other e-service options. 


\section{References}

Abbad, M., Abed, J., \& Abbad, M. (2012). The development of e-banking in developing countries in the Middle East. Journal of Finance, Accounting and Management, 3(2), 107-123.

Abu Shanab, E., \& Pearson, J. (2007). Internet banking in Jordan: The unified theory of acceptance and use of technology (UTAUT) perspective. Journal of Systems and Information Technology, 9(1), 78-97. http://dx.doi.org/10.1108/13287260710817700

Agarwal, R., \& Prasad, J. (1998). The antecedents and consequents of user perceptions in information technology adoption. Decision Support $\quad$ Systems, $22(1), \quad 15-29$. http://dx.doi.org/10.1016/S0167-9236(97)00006-7

Ajzen, I. (1985). From intentions to actions: A theory of planned behavior. In J. Kuhl \& J. Beckman (Eds.), Action-control: From cognition to behavior (pp. 11-39). Heidelberg: Springer. http://dx.doi.org/10.1007/978-3-642-69746-3_2

Al Qeisi, K., \& Al-Abdallah, G. (2013). Internet banking adoption in Jordan: A behavioral approach. International Journal of Marketing Studies, 5(6), 84-108. http://dx.doi.org/10.5539/ijms.v5n6p84

Aladwani, A., \& Palvia, P. (2002). Developing and validating an instrument for measuring user-perceived web quality. Information \& Management, 39(6), 467-476. http://dx.doi.org/10.1016/S0378-7206(01)00113-6

Alawadhi, S., \& Morris, A. (2009). Factors affecting the adoption of e-government services. Journal of Software, 4(6), 584-590. http://dx.doi.org/10.4304/jsw.4.6.584-590

AlGahtani, S., Hobana, G., \& Wang, J. (2007). Information technology (IT) in Saudi Arabia: Culture and the acceptance and use of IT. Information \& Management, 44(8), 681-691. http://dx.doi.org/10.1016/j.im.2007.09.002

AlImarah, A., Zwain, A., \& Al-Hakim, L. (2013). The adoption of e-government services in the Iraqi Higher Education Context: An application of the UTAUT model in the University of Kufa. Journal of Information Engineering and Applications, 3(10), 77-84.

AlKhunaizan, A., \& Love, S. (2012). What drives mobile commerce? An empirical evaluation of the revised UTAUT model. International Journal of Management and Marketing Academy, 2(1), 82-99.

AlMashaqba, F., \& Nassar, M. (2012). Modified UTAUT model to study the factors affecting the adoption of mobile banking in Jordan. International Journal of Sciences: Basic and Applied Research (IJSBAR), 6(1), 83-94.

AlOtaibi, M. (2013). Determinants of mobile service acceptance in Saudi Arabia: A revised UTAUT model. International Journal of E-Services and Mobile Applications, 5(3), $43-61$. http://dx.doi.org/10.4018/jesma.2013070103

AlQeisi, K., Dennis, C., Alamanos, E., \& Jayawardhena, C. (2014). Website design quality and usage behavior: Unified theory of acceptance and use of technology. Journal of Business Research, 67(11), 2282-2290. http://dx.doi.org/10.1016/j.jbusres.2014.06.016

Al-Shafi, S., \& Weerakkody, V. (2010). Factors affecting e-government adoption in the state of Qatar. European and Mediterranean Conference on Information Systems. Retrieved from http://bura.brunel.ac.uk/handle/2438/6266

AlShehri, M., Draw, S., \& AlGhamdi, R. (2013). Analysis of citizen acceptance of e-government services: Applying the UTAUT model.

Alwahaishi, S., \& Václav, S. (2013). Consumers' acceptance and use of information and communications technology: A UTAUT and flow based theoretical model. Journal of Technology Management \& Innovation, 8(2), 61-73. http://dx.doi.org/10.4067/S0718-27242013000200005

Anandarajan, M., Igbaria, M., \& Anakwe, U. (2002). IT Acceptance in a Less-Developed country: A motivational factor perspective. International Journal of Information Management, 22(1), 47-65. http://dx.doi.org/10.1016/S0268-4012(01)00040-8

Attuquayefio, S., \& Addo, H. (2014). Review of studies with UTAUT as conceptual framework. European Scientific Journal, 10(8), 249-258.

Byrne, B. (2010). Structural equation modeling with AMOS (2nd ed.). NY: Routledge.

Byrne, B., \& Stewart, S. (2006). Teacher's Corner: The MACS approach to testing for Multigroup Invariance of 
a second-order Structure: A walk through the process. Structural Equation Modeling: A Multidisciplinary Journal, 13(2), 287-321. http://dx.doi.org/10.1207/s15328007sem1302_7

Byrne, B., Stewart, S., Kennard, B., \& Lee, P. (2007). The beck depression inventory-II: Testing for measurement equivalence and factor means differences across Hong Kong and American Adolescents. International Journal of Testing, 7(3), 293-309. http://dx.doi.org/10.1080/15305050701438058

Cheung, G., \& Lau, R. (2008). Testing mediation and suppression effects of latent variables: Bootstrapping with structural equation models. Organizational Research Methods, 11(2), 296-325. http://dx.doi.org/10.1177/1094428107300343

Davis, F. (1989). Perceived usefulness, perceived ease of use, and user acceptance of information technology. MIS Quarterly, 13(3), 319-340.

Davis, F., \& Venkatesh, V. (1996). A critical assessment of potential measurement biases in the technology acceptance model: Three experiments. International Journal of Human Computer Studies, 45(1), 19-45. http://dx.doi.org/10.1006/ijhc.1996.0040

Davis, F., Bagozzi, R., \& Warshaw, P. (1989). User acceptance of computer technology: A comparison of two theoretical models. Management Science, 35(8), 982-1003. http://dx.doi.org/10.1287/mnsc.35.8.982

Dijk, J., Peters, O., \& Ebbers, W. (2008). Explaining the acceptance and use of government internet services: A multivariate analysis of 2006 survey data in Netherlands. Government information Quarterly, 25(3), 375-399. http://dx.doi.org/10.1016/j.giq.2007.09.006

Dwivedi, Y., Rana, N., Chen, H., \& Williams, M. (2011). A Meta -analysis of the Unified Theory of Acceptance and Use of Technology (UTAUT). IFIP Advances in Information and, Communication Technology, 366, 155-170. http://dx.doi.org/10.1007/978-3-642-24148-2_10

Elbeltagi, I., McBride, N., \& Hardaker, G. (2005). Evaluating the factors affecting DSS usage by senior managers in local authorities in Egypt. Journal of Global Information Management, 13(2), 42-65. http://dx.doi.org/10.4018/jgim.2005040103

El-Kasheir, D., Ashour, A., \& Yacout, O. (2009). Factors affecting continued usage of internet banking among Egyptian customers. Communications of the IBIMA, 9(29), 252-263.

Floh, A., \& Treiblmaier, H. (2006). What keeps the e-banking customers loyal? A multi-group analysis of the moderating role of customer characteristics on e-loyalty in the finance s ervice industry. Journal of Electronic Commerce Research, 7(2), 97-110.

French, B., \& Finch, W. (2006). Confirmatory factor analytic procedures for the determination of measurement invariance. Structural Equation Modeling: A Multidisciplinary Journal, 13(3), 378-402.

Hair, J., Black, W., Babin, B., \& Anderson, R. (2006). Multivariate data analysis: A global perspective. New Jersey: Prentice Hall. http://dx.doi.org/10.1207/s15328007sem1303_3

International Telecommunication Union Reports. (2012). Country profile. Retrieved from http://www.itu.int/net4/itu-d/icteye/CountryProfile.aspx

International Telecommunication Union Reports. (2013). Measuring the information society. Retrieved from http:// www.itu.int/en/ITU-D/.../mis2013/MIS2013_without_Annex_4.pdf

Jaradat, I., \& Banikhalid, M. (2013). Undergraduate students adoption of website-service quality by applying the Unified Theory of Acceptance and Use of Technology (UTAUT) in Jordan. International Journal of Interactive Mobile Technologies, 7(3), 22-29.

Jonsson, A. (2013). Information system usage: A study in the Middle East. Unpublished Master thesis. Retrieved from http://www.diva-portal.org/smash/get/diva2:639473/FULLTEXT01.pdf

Karahanna, E., Straub, D., \& Chervany, N. (1999). Information technology adotion across time: A cross sectional comparision of pre-adotion and post-adotion beliefs. MIS Quarterly, 23(2), 183-213.

Khushman, S., Todman, A., \& Amin, S. (2010). The acceptance of e-business websites in Arab countries. Oxford Research Forum Journal, 3(2), 33-47.

King, W., \& He, J. (2006). A meta-analysis of the technology acceptance model. Information and Management, 43(6), 740-755. http://dx.doi.org/10.1016/j.im.2006.05.003

McCoy, S., Galletta, D., \& King, W. (2007). Applying TAM across cultures: The need for caution. European Journal of Information Systems (EJIS), 16(1), 81-90. http://dx.doi.org/10.1057/palgrave.ejis.3000659 
Morris, M., \& Venkatesh, V. (2000). Age differences in technology adoption decisions: Implications for a changing work force. Personnel Psychology, 53(2), 375-403.

Nassuora, B. (2012). Students acceptance of mobile learning for higher education in Saudi Arabia. International Journal of Learning Management Systems, 1(1), 1-9.

Oshlyansky, L., Cairns, P., \& Thimbleby, H. (2007). Validating the Unified Theory of Acceptance and Use of Technology (UTAUT) tool cross-culturally. Proceedings of the 21st BCS HCI Group Conference. British Computer Society, 2.

Rose, G., \& Straub, D. (1998). Predicting general IT use: Applying TAM to the Arab world. Journal of Global Information Management, 6(3), 39-46.

Rouibah, K. (2008). Social usage of instant messaging by individuals outside the workplace in Kuwait: A structural equation model. Information Technology \& People, 21(1), 34-68. http://dx.doi.org/10.1108/09593840810860324

Salim, B. (2012). An application of UTAUT model for acceptance of social media in Egypt: A statistical study. International Journal of Information Science, 2(6), 92-105. http://dx.doi.org/10.5923/j.ijis.20120206.05

Straub, D. (1994). The effect of culture on IT diffusion: E-Mail and Fax in Japan and the U.S. Information Systems Research, 5(1), 23-47.

Straub, D., Keil, M., \& Brenner, W. (1997). Testing the technology acceptance model across cultures: A three country study. Information \& Management, 33(1), 1-11. http://dx.doi.org/10.1016/S0378-7206(97)00026-8

Straub, D., Loch, K., \& Hill, C. (2001). Transfer of information technology to the Arab World: A test of cultural influence modeling. Journal of Global Information Management, 9(4), 6-27. http://dx.doi.org/10.4018/jgim.2001100101

Taiwo, A., \& Downe, A. (2013). The theory of user acceptance and use of technology (UTAUT): A meta-analytic review of empirical findings. Journal of Theoretical and Applied Information Technology, 49(1), 48-58.

Taylor, S., \& Todd, P. (1995). Understanding information technology usage: A test of competing models. Information Systems Research, 6(2), 144-176. http://dx.doi.org/10.1287/isre.6.2.144

Venkatesh, V. (1999). Creation of favorable user perceptions: exploring the role of intrinsic motivation. MIS Quarterly, 23(2), 239-260.

Venkatesh, V., \& Bala, H. (2008). Technology acceptance model 3 and a research agenda on interventions. Decision Sciences, 39(2), 273-315. http://dx.doi.org/10.1111/j.1540-5915.2008.00192.x

Venkatesh, V., \& Davis, F. (2000). A theoretical extension of the technology acceptance model: Four longitudinal field studies. Management Science, 46(2), 186-204. http://dx.doi.org/10.1287/mnsc.46.2.186.11926

Venkatesh, V., Morris, M., \& Ackerman, P. (2000). A longitudinal field investigation of gender differences in individual technology adoption decision-making processes. Organizational Behavior and Human Decision Processes, 83(1), 33-60.

Venkatesh, V., Morris, M., Davis, G., \& Davis, F. (2003). User acceptance of information technology: Toward a unified view. MIS Quarterly, 27(3), 425-478.

Wang, Y. S., \& Shih, Y. W. (2009). Why do people use information Kiosks? A validation of the Unified Theory of Acceptance and use of Technology. Government Information Quarterly, 26(1), 158-165.

World Bank Group. (2013). Retrieved 12th Dec., 2013, from http://www.worldbank.org/ 


\section{Appendix 1}

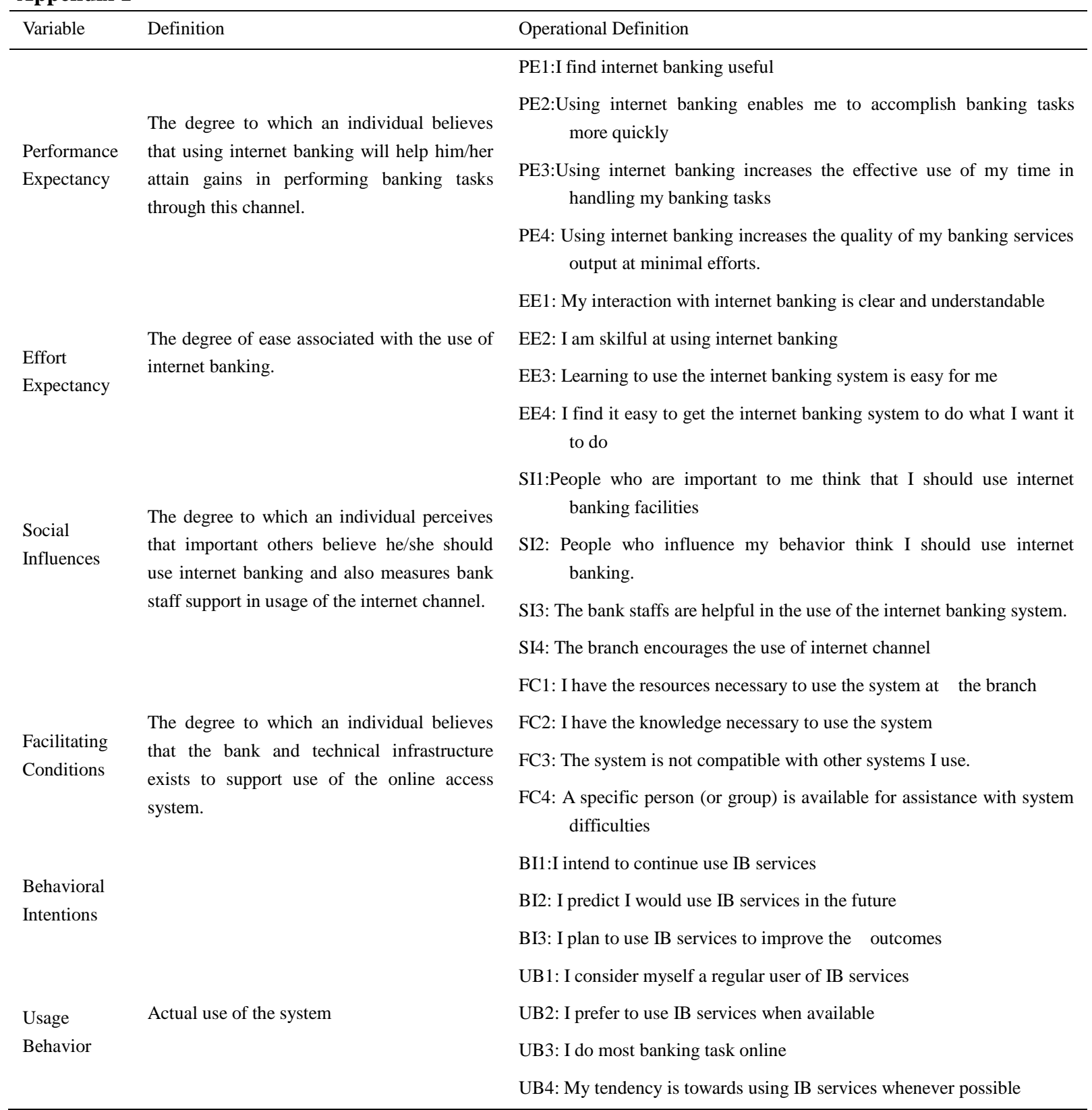

Source: Venkatesh et al. (2003) with adaptation to internet banking usage behaviour.

\section{Copyrights}

Copyright for this article is retained by the author(s), with first publication rights granted to the journal.

This is an open-access article distributed under the terms and conditions of the Creative Commons Attribution license (http://creativecommons.org/licenses/by/3.0/). 